\title{
Giant right ventricle secondary to severe pulmonary hypertension
}

\author{
Kunal Kishor Jha, ${ }^{1}$ Nuwadatta Subedi, ${ }^{2}$ Durgesh Prasad Chaudhary, ${ }^{3}$ Manoj Lamsal ${ }^{4}$
}

'Department of Critical Care Medicine, Geisinger Medical Center, Danville, Pennsylvania, USA

${ }^{2}$ Gandaki Medical College, Pokhara, Nepal ${ }^{3}$ Department of Internal Medicine, Norvic International Hospital, Kathmandu, Nepal

${ }^{4}$ Department of Internal Medicine, Tribhuvan University Institute of Medicine, Maharajgunj, Nepal

\section{Correspondence to} Dr Kunal Kishor Jha, kunaljhamd@gmail.com

Accepted 9 March 2017

\section{DESCRIPTION}

A man aged 64 years presented to emergency department with chest pain and shortness of breath. On cardiac auscultation, he had loud P2 and parasternal heave; however, lung auscultation was normal. Bilateral lower limb pitting oedema was present. $\mathrm{CBC}, \mathrm{CMP}$ and cardiac biomarkers were normal. D-dimer and CT chest were performed and it excluded pulmonary embolism. His EKG was suggestive of right ventricular strain. He was being treated for systemic and pulmonary hypertension, taking carvedilol $3.125 \mathrm{mg}$ two times per day, furosemide $40 \mathrm{mg}$ once daily, sildenafil $20 \mathrm{mg}$ three times a day, treprostinil $0.5 \mathrm{mg}$ two times per day, amlodipine $2.5 \mathrm{mg}$ two times per day, atorvastatin $40 \mathrm{mg}$ once daily, aspirin $81 \mathrm{mg}$ once daily and clopidogrel $75 \mathrm{mg}$ once daily. Trans-thoracic echocardiography showed his systolic function was normal, his estimated ejection fraction was $60-65 \%$ with markedly dilated right ventricle (RV), no valve defect was detected and peak pulmonary artery pressure (Ppa) was $80 \mathrm{~mm} \mathrm{Hg}$. On coronary angiography, there was $60 \%, 50 \%$ and $60 \%$ stenosis detected in the left main artery, left anterior descending and right coronary artery, respectively. On cardiac catheterisation, RV was massively dilated and hypokinetic, the left ventricle (LV) was normal in size and function with preserved ejection fraction (figure 1, videos 1 and 2), his pulmonary artery pressure was $76 \mathrm{~mm} \mathrm{Hg}$. On cardiac catheter haemodynamics, his mean right atrial pressure was $64 \mathrm{~mm} \mathrm{Hg}, \mathrm{RV}$ pressure was $66 / 20 \mathrm{~mm} \mathrm{Hg}$ and pulmonary artery wedge pressure was 17/14 $\mathrm{mm} \mathrm{Hg}$. On echocardiography, tricuspid annular plane systolic excursion was $<0.9 \mathrm{~cm}$, and TR jet velocity was $3.08 \mathrm{~m} / \mathrm{s}$. An apical four-chamber view shows dilation of RV (video 3). NT-proBNP value was $578 \mathrm{pg} / \mathrm{mL}$. Symptomatic management with oxygen, intravenous fluid and home medications were continued. Owing to severe pulmonary hypertension and enlarged RV, atrial septostomy was offered. He refused to undergo surgery or consultation and went to another institution for further evaluation.

Normal RV have a thinner wall, are crescent shape and have greater compliance than the LV. RV enlargement is defined as the RV being greater than the two-thirds the size of the LV on the apical fourchamber view of echocardiography. ${ }^{1}$ Pulmonary arterial hypertension (PAH) is associated with changes in the pulmonary vasculature and subsequently RV. The severity of symptoms and prognosis of PAH are strongly associated with RV function. $^{2}$

In milder forms of $\mathrm{PAH}$, the reduction in pulmonary vascular resistance (PVR) has beneficial effect on the RV, but these effects may not occur in severe PAH. ${ }^{2}$ Although current pharmacological treatments of PAH reduce RV load, they do not reduce its pressure or output and RV failure may continue to progress, especially in those with severe $\mathrm{PAH}$. Various haemodynamic factors such as mean Ppa, right atrial pressure, cardiac output and cardiac index are directly related to RV function and it has been identified as significant predictors of mortality. ${ }^{3}$ Despite its significant clinical implications, these factors and the effects of current PAH specific therapies on the RV have not garnered

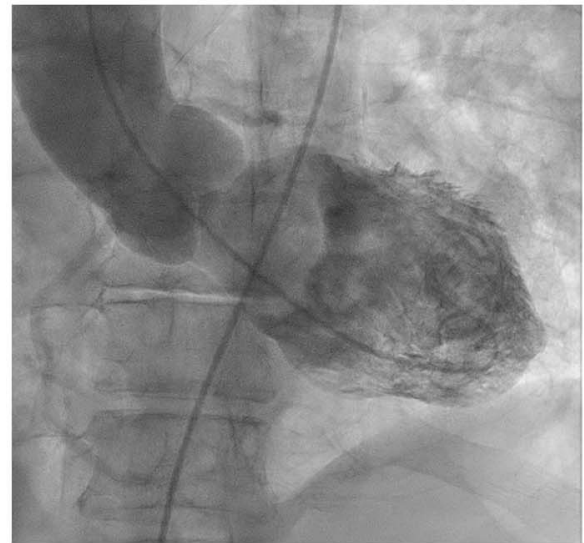

LEFT VENTRICLE

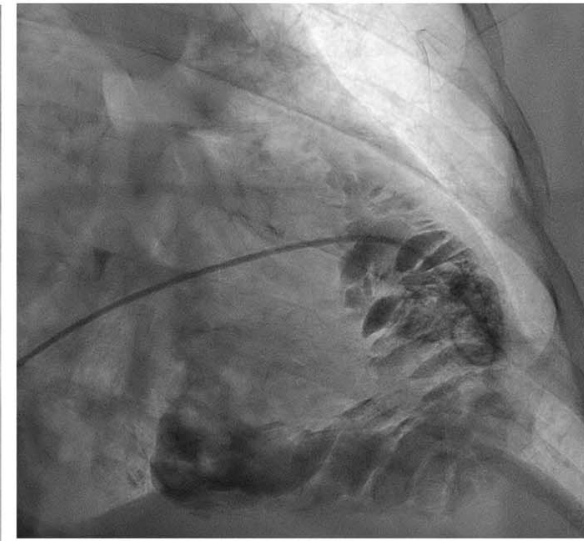

RIGHT VENTRICLE

Figure 1 Massively dilated right ventricle and normal left ventricle can be seen on right and left heart catheterisation, respectively. 


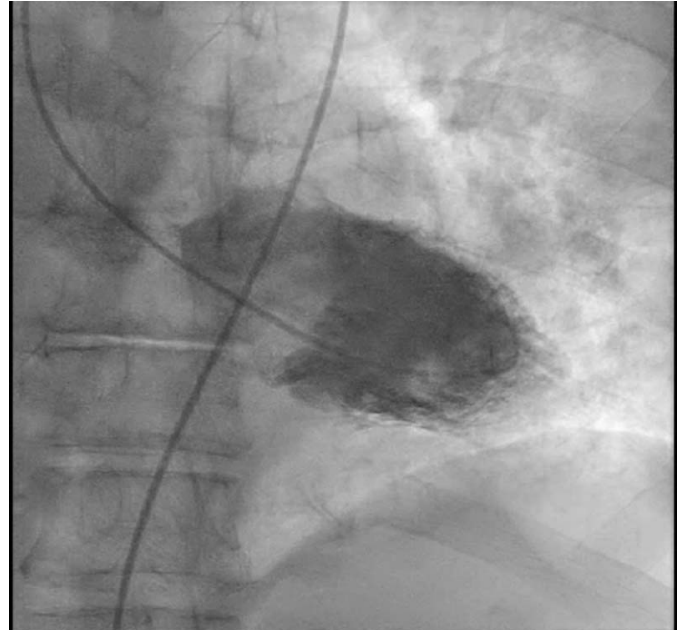

Video 1 Left ventricle on left heart catheterisation.

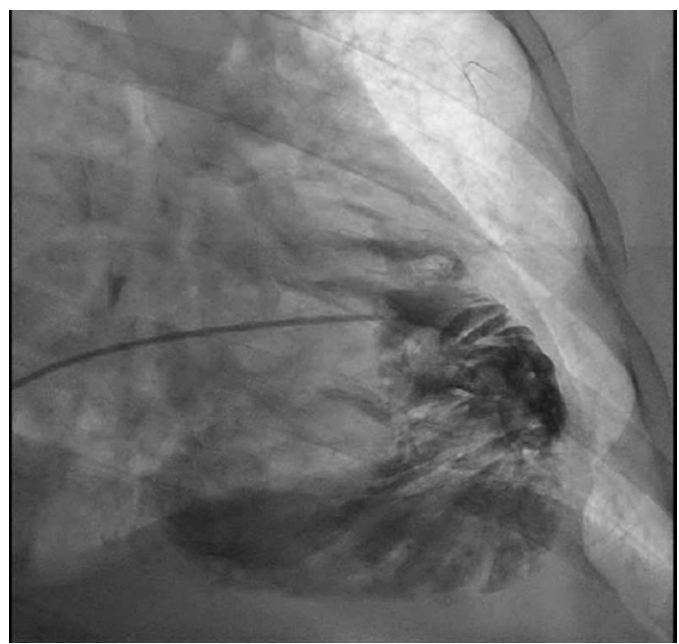

Video 2 Giant right ventricle on right heart catheterisation.

enough research interest. ${ }^{2}$ Greater consideration for means of assessing the presence of overt and subclinical RV failure and strategies to support the RV in PAH is required.

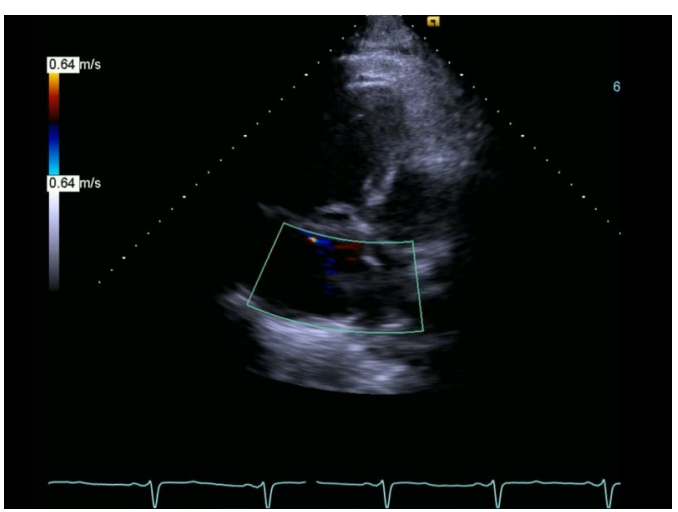

Video 3 An apical four-chamber view showing right ventricle dilation.

\section{Learning points}

- Pulmonary arterial hypertension (PAH) is associated with changes in the pulmonary vasculature and subsequently right ventricle (RV). The severity of symptoms and prognosis of PAH are strongly associated with RV function.

- Although current pharmacological treatments of PAH reduce RV load, they do not reduce its pressure or output and RV failure may continue to progress.

- Greater consideration for means of assessing the presence of overt and subclinical RV failure and strategies to support the $\mathrm{RV}$ in PAH is required.

Contributors KKJ compiled the case history and investigations, critically reviewed and prepared the manuscript. NS, DPC and ML analysed, critically reviewed the data and prepared the manuscript.

Competing interests None declared.

Patient consent Obtained.

Provenance and peer review Not commissioned; externally peer reviewed.

\section{REFERENCES}

1 Peterson D, Arntfield RT. Critical care ultrasonography. Emerg Med Clin North Am 2014;32:907-26

2 Vonk Noordegraaf A, Galiè N. The role of the right ventricle in pulmonary arterial hypertension. Eur Respir Rev 2011;20:243-53.

3 Humbert M, Sitbon O, Chaouat A, et al. Survival in patients with idiopathic, familial, and anorexigen-associated pulmonary arterial hypertension in the modern management era. Circulation 2010;122:156-63.

Copyright 2017 BMJ Publishing Group. All rights reserved. For permission to reuse any of this content visit

http://group.bmj.com/group/rights-licensing/permissions.

BMJ Case Report Fellows may re-use this article for personal use and teaching without any further permission.

Become a Fellow of BMJ Case Reports today and you can:

- Submit as many cases as you like

- Enjoy fast sympathetic peer review and rapid publication of accepted articles

- Access all the published articles

- Re-use any of the published material for personal use and teaching without further permission

For information on Institutional Fellowships contact consortiasales@bmjgroup.com

Visit casereports.bmj.com for more articles like this and to become a Fellow 